\section{Shots in the Dark: The Wayward Search for an AIDS Vaccine}

Jon Cohen has presented a provocative and remarkably detailed account of the first 20 years of the quest towards an AIDS vaccine. In 1981, it was a new disease. By 1983, there was a causative virus that one could culture. Yet 20 years later AIDS is an epidemic of tragic proportions for Africa and the fourth leading cause of death in the world. The biomedical establishment successfully mobilized to produce antiviral drugs, but faltered in its effort to produce a vaccine. Was there truly "no real leadership," "no real funding," and "no real sense of urgency"? Or, had the virus-a relentless 10,000 base pairs of stealth and persistence-confounded conventional approaches to vaccines? Cohen movingly opens the account in the Reagan White House at a 1982 press conference where the disease known as the 'gay plague' is handled in a way that draws laughter. He ends at the $13^{\text {th }}$ International AIDS conference in Durban where South African President Thabo Mbeki in an opening address blames AIDS on poverty not HIV-1, and where an impassioned Nelson Mandela closed the congress with a plea for the recognition of the viral origin of AIDS, the thwarting of maternal-infant transmission and the development of a vaccine.

So, given a lack of focused political leadership, why else have the efforts to develop an AIDS vaccine been "shots in the dark"? Cohen explores how both big pharmaceutical and biotech companies set out to produce AIDS vaccines as soon as HIV-1 was molecularly cloned. Modeled on the recently successful hepatitis B vaccine, the favored approach was to produce the HIV-1 envelope glycoprotein and then to inoculate this protein in the presence of an adjuvant to raise protective antibody. Envelope proteins were produced in yeast or cell cultures and antibody was raised in rodents and non-human primates. Two chimpanzees were protected against a challenge infection. Preparations were initiated for a Phase III efficacy trial. But then, sera from the volunteers in the small scale safety/dosing trials that precede efficacy trials were examined for their ability to block infections with patient isolates of HIV-1 as opposed to the laboratory adapted strains of HIV-1 that had been used to produce the vaccine. The neutralization failed. Immunized macaques challenged with viruses that were not neutralized by raised antibody became infected and developed dis-

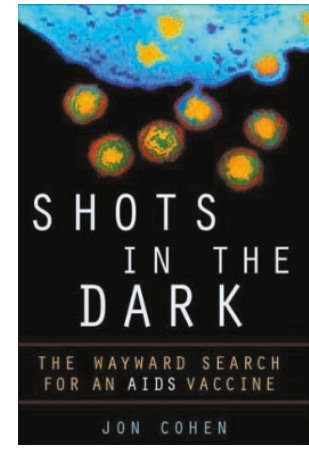
viruses, a modality that provided the first successful polio vaccine and that Salk again championed, became mired in false positives. The protective antibody responses turned out to be against celluIar proteins that had budded with the virus rather than against the well-camouflaged target, the viral-envelope protein.

Meanwhile, amid the swirl of ethical issues surrounding physicians volunteering to test a non-approved live attenuated vaccine and the growing issue of whether trial participants in developing countries should receive first world treatment if they ease. The United States National Institute of Allergy and Infectious Disease mustered its committees of experts. The first committee approved continuing with the efficacy trial. The second, at an impasse, issued a muddled statement, which translated into government support for the efficacy trial being cancelled. The vaccine effort had foundered. Industry had been shot in the foot. An approach that was not likely to betheanswer to a vaccine, but could have provided a component for a successful vaccine, had been pulled from the critical trial. It would be up to inspired private financing and the willingness of Thailand, a country which then had soaring AIDS rates (the Thais have since mounted an education program and put condoms in hotel rooms), to provide the momentum to take trials forward.

Cohen recounts how academic and government researchers took the lead in exploring two classic but potentially riskier approaches to an AIDS vaccine: live attenuated viruses and whole inactivated viruses. Both of these approaches hold the risk of a virulent virus infection; the live atten uated virus can mutate to a more virulent form or cause disease in an immunosuppressed individual, and the killed virus can be incompletely inactivated. Still, both held early promise. A group of 1,000 physicians even offered to test the safety of the live attenuated virus. But then the live attenuated viruses began to 'break through'-initially in infant monkeys (who have immature immune systems) and, with time, in adult monkeys. The formula for sufficient attenuation while retaining the ability to raise protective immunity became a slippery slope. Whole inactivated became infected, new approach es to vaccines were emerging from laboratory re search. These new approaches were complemented by studies that provided at least some information about the types of immune responses that were controlling infections in the few individuals blessed with long-term non-progressive infections and commercial sex workers who remained virus free. Much of this research was investigator-initiated or the result of work in individual academic or government laboratories. Cohen tells of the growing realization of the importance of cell-mediated immunity, especially CD8 T cells, in the control of immunodeficiency virus infections and a burgeoning ability to design vaccines that could initiate cellular as well as humoral immunity. The most effective way for a vaccine to raise CD8 T cells is for the vaccinating protein to be produced in cells of the vaccinated individual. Production of a viral protein in cells allows peptide fragments of the protein to be loaded onto histocompatibility antigens and presented to the immune system, a key step in initiating a CD8 T-cell response. Cohen reports the seminal studies in the early 1980s showing that recombinant viruses, such as the poxviruses used during the eradication of smallpox, could safely be used to carry immunizing proteins into cells. He also tells (in a single paragraph) of the initially heretical studies showing that purified DNA could be taken up by cells to produce immunizing proteins that raised both antibody and CD8 T cells.

Not all of the progress was in the lab. Cohen recounts how within the US, President Clinton recognized the importance of AIDS and made vaccine develop- 
ment a national priority. He tells of the revamping of AIDS funding at the National Institutes of Health and of important new dollars and support mechanisms for AIDS vaccines. These included seed funds for novel ideas, support for targeted collaborative programs, contracts for vaccine production by industry, and the expansion of the capabilities of a vaccine trials networks. On the private side, the International AIDS Vaccine Initiative (IAVI) spearheaded concept development and targeted trials. IAVI, initially funded on a shoestring but working closely with researchers, ethicists and epidemiologists from developing countries and now partially funded by the Gates Foundation, actively moves vaccine concepts into trials. The AIDS Vaccine Advocacy Coalition and other primarily gay efforts effectively and re lentlessly lobbied for the infected, and for vaccine development.

As Cohen brings his account to a close, he argues that the AIDS vaccine ef- fort needs a 'M arch of Dollars' to provide focused financing to fill research gaps and fund head-to-head comprehensive monkey trials comparing candidate vaccines. He argues for political and public support. First world as well as third world leaders must acknowl edge the disease and place priority on a vaccine. As citizens, we must be willing to champion control of a disease that is spread by promiscuity and drugs and not a more socially correct route such as aerosols. He tells of how over one million parents of second graders filled re quest forms for their child to be a 'Polio Pioneer' in a placebo-controlled trial and how the March of Dimes, to ensure a supply of the vaccine, guaranteed $\$ 9,000,000$ (a very large sum in 1954) for manufacturing vaccine to be ready for distribution if the efficacy trial demonstrated prevention of polio. The reader ponders whether we would volunteer our middle school children (the age our children become at risk) to test a promis- ing AIDS vaccine? Whether-given the hope of a successful vaccine-we would put down an advance on vaccine production?

Cohen continues to report on AIDS vaccines for Scien ce magazine. His recent articles highlight a '48 lab chief' effort of a large pharmaceutical company using recombinant viral as well as adjuvanted DNA approaches to a vaccine and feature the control of highly virulent challenge infections in two macaque trials that successfully raised anti-viral T cells as well as antibodies. Both of the successful trials used approaches to vaccines developed since the advent of the AIDS epidemic: priming and boosting with DNA adjuvanted two days later with IL-2, or priming with DNA and boosting with a recombinant poxvirus. The bright side to Shots in the Dark is that with time Jon Cohen should be able to write an equally engrossing and informed tale of the science, the politics and the ethics of the battle won.
Long ARTICLE

A bstract $\rightarrow$ 100-150 words of simple prose, A no technical details. Focus on general advance and implications. No references.

$M$ ain text $\rightarrow$ (3000 word max) Separate sections for introduction, results, discussion and methods (800 word max). Subheadings for results and methods. Reference max of 45. Display items: 6 max including tables, figures can be multipaneled.

\section{Short Article}

bstract $\rightarrow$ One terse paragraph of 100-200 words, with references, A providing background, main results and implications. Simple prose, no technical details. This is the only introductory material in a short article.

ain text $\rightarrow$ Results and discussion (1500 word max) immediately follows the abstract, referencing first display item. Subheadings for

\section{Methods}

$\rightarrow$ Remove all methodology and discussion from the figure legends. This includes concentrations, incubation times temperatures, and so on. $\rightarrow$ Oligonucleotide sequences are written 5'-GATCGACT-3' (note: no spaces between the upper-case nucleotide letters).

$\rightarrow$ Provide locations of manufacturers, without abbreviations (city and state, for US; city and country for non-US): (Vector, Burlingame, California).

$\rightarrow$ Units except for \% should be preceded by a space (7 ㅇ; $12 \mathrm{mM} ; 55 \%$ ). $\rightarrow$ Use symbol font for "micro": $\mu \mathrm{M}$, not uM. If using Microsoft Word, go to "insert/symbols" to make sure the symbols do not drop out when the font changes.

\section{General Style Points}

$\rightarrow$ Use the active, not passive voice throughout the text: "We examined the retinas of the mice.", not "The retinas of the mice were examined."

Abbreviations are not used in abstracts. Spell out abbreviations at first use in body of text.

$\rightarrow$ Mutants are referred to with superscript as follows: "Clqa ${ }^{+++"}$ and not "Clqa +4 " or " $+1+$ ". Gene designation only is italicized; the designation for 'zygosity' is superscripted and not italicized.

$\rightarrow$ The "P" for P values is upper-case and italicized.

$\rightarrow$ The " $n$ " for number islower-case and italicized.

$\rightarrow$ Kilodalton is abbreviated kDa.

$\rightarrow$ Full postal and email address is required for each author.

$\rightarrow$ We strongly recommend that the article be read by a native Englishspeaking scientist not directly related to your field of research.

$\rightarrow$ In thetext, refer to figures as (Fig. 1a, b and c) or (Table) in parentheses, at end of text referring to figure (not "As shown in Fig. 1,...")

\section{DISPLAY ITEMS}

$\rightarrow$ In the text, refer to figures as (Fig. 1a, b and c) or (Table) in parentheses, at end of text referring to figure (not "As shown in Fig. 1,...")

$\rightarrow$ "Fig." is abbreviated and followed with a period; " $F$ " is upper-case (Fig.).

$\rightarrow$ Panel letter should be lower-case, and italicized.

$\rightarrow$ Figures must appear in text in order: $1 \mathrm{a}, 1 \mathrm{~b}, 2 \mathrm{a}, 2 \mathrm{~b}$.

$\rightarrow$ Tables must be supplied as part of a simple word document, if possible, convert the table to text usings tabs to separate entries.

$\rightarrow$ Provide a brief title (one sentence of less than 10 words) describing the figure or table as a whole in the figure legend.

$\rightarrow$ Symbols should be identified in figure caption only; not in the image itself. 